\title{
Psychotropic drug-induced hyponatremia: results from a drug surveillance program-an update
}

\author{
Johanna Seifert ${ }^{1}$ (1) $\cdot$ Martin Letmaier $^{2} \cdot$ Timo Greiner $^{3} \cdot$ Michael Schneider $^{4} \cdot$ Maximilian Deest $^{1}$. \\ Christian K. Eberlein ${ }^{1} \cdot$ Stefan Bleich ${ }^{1} \cdot$ Renate Grohmann $^{5} \cdot$ Sermin Toto $^{1}$
}

Received: 8 May 2021 / Accepted: 18 June 2021 / Published online: 1 July 2021

(C) The Author(s) 2021

\begin{abstract}
Hyponatremia (HN) is the most common electrolyte imbalance (defined as a serum sodium concentration $\mathrm{Na}(\mathrm{S})$ of $<130 \mathrm{mmol} / \mathrm{l}$ ) and often induced by drugs including psychotropic drugs. AMSP (Arzneimittelsicherheit in der Psychiatrie) is a multicenter drug surveillance program that assesses severe or unusual adverse drug reactions (ADRs) occurring during treatment with psychotropic drugs. This study presents data from 462,661 psychiatric inpatients treated in participating hospitals between 1993 and 2016 and serves as an update of a previous contribution by Letmaier et al. (JAMA 15(6):739-748, 2012). A total of 210 cases of $\mathrm{HN}$ were observed affecting $0.05 \%$ of patients. $57.1 \%$ of cases presented symptomatically; $19.0 \%$ presented with severe symptoms (e.g., seizures, vomiting). HN occurred after a median of 7 days following the first dose or dose increase. Incidence of $\mathrm{HN}$ was highest among the two antiepileptic drugs oxcarbazepine (1.661\% of patients treated) and carbamazepine $(0.169 \%)$, followed by selective serotonin-norepinephrine reuptake inhibitors (SSNRIs, $0.088 \%$ ) and selective serotonin reuptake inhibitors $(0.071 \%)$. Antipsychotic drugs, tricyclic antidepressants, and mirtazapine exhibited a significantly lower incidence of HN. The risk of HN was 16-42 times higher among patients concomitantly treated with other potentially $\mathrm{HN}$-inducing drugs such as diuretic drugs, angiotensin-converting-enzyme inhibitors, angiotensin II receptor blockers, and proton pump inhibitors. Female SSNRI-users aged $\geq 65$ years concomitantly using other HN-inducing drugs were the population subgroup with the highest risk of developing HN. The identification of high-risk drug combinations and vulnerable patient subgroups represents a significant step in the improvement of drug safety and facilitates the implementation of precautionary measures.
\end{abstract}

Keywords Adverse drug reaction $\cdot$ Antidepressant drugs $\cdot$ Antiepileptic drugs $\cdot$ Antipsychotic drugs $\cdot$ Drug safety $\cdot$ Serum sodium concentration

Johanna Seifert

seifert.johanna@mh-hannover.de

1 Department of Psychiatry, Social Psychiatry, and Psychotherapy, Hannover Medical School, Carl-Neuberg-Straße 1, 30625 Hannover, Germany

2 Department of Medical Psychology and Psychotherapy, Medical University of Graz, Auenbruggerplatz 2, 8036 Graz, Austria

3 Institute for Clinical Pharmacology of the Brandenburg Medical School, Immanuel Klinik Rüdersdorf, Seebad 82/83, 15562 Rüdersdorf, Germany

4 Department of Psychiatry and Psychotherapy of the Brandenburg Medical School, Immanuel Klinik Rüdersdorf, Seebad 82/83, 15562 Rüdersdorf, Germany

5 Department of Psychiatry and Psychotherapy, Ludwig Maximilian University of Munich, Nussbaumstr. 7, 80336 Munich, Germany

\section{Introduction}

Hyponatremia $(\mathrm{HN})$ is characterized by low serum sodium concentration (generally $<135 \mathrm{mmol} / \mathrm{l}$ ) and is the most common type of electrolyte imbalance (Dineen et al. 2017). In this study, $\mathrm{HN}$ was set at serum sodium concentration $\mathrm{Na}(\mathrm{S})$ below $130 \mathrm{mmol} / 1$, as it is more relevant to clinical practice (Spasovski et al. 2014; Mazhar et al. 2021). It is estimated that $15-20 \%$ of all patients admitted to the hospital suffer from this condition. The severity of symptoms is highly variable ranging from a complete absence of symptoms to mild symptoms such as headache, nausea, and imbalance, to serious symptoms such as seizures, cognitive impairment, and coma. The intensity of symptoms is associated with how quickly $\mathrm{Na}(\mathrm{S})$ decreases. A sudden onset drop $(<48 \mathrm{~h})$ of $\mathrm{Na}(\mathrm{S})$ causes more dramatic clinical symptoms than a 
gradual decrease (Spasovski et al. 2014). The severe neurological symptoms of $\mathrm{HN}$ are caused by swelling of the brain cells resulting from redistribution of fluids from the extracellular to the intracellular compartment. These changes lead to an increase in intracranial pressure. When HN develops slowly over the course of several days or weeks, the body has more time to adapt and react to these changes resulting in a different array of major health complications. It is well-known that chronic $\mathrm{HN}$ is associated with a multitude of adverse health outcomes such as reduced cognitive functions, unsteadiness, falls (Renneboog et al. 2006), fractures, and osteoporosis (Gankam Kengne et al. 2008; Verbalis et al. 2010). Moreover, mild $\mathrm{HN}$ has proven to be an independent risk factor of death within the ambulatory setting (Gankam-Kengne et al. 2013).

$\mathrm{Na}(\mathrm{S})$ is managed by changes in the intake or output of water. While the specific underlying causes of $\mathrm{HN}$ are diverse, two main mechanisms result in low $\mathrm{Na}(\mathrm{S})$ : water retention and - more frequently — loss of sodium. Depending on the underlying cause of $\mathrm{HN}$, the circulating volume can be decreased, normal, or increased thus resulting in hypovolemic, euvolemic, or hypervolemic HN (Spasovski et al. 2014). Hypovolemic HN is caused by a depletion of extracellular fluid for example due to excessive sweating, vomiting, or most commonly, associated with the use of diuretic drugs (DIUs). Hypervolemic HN can be the result of severe illness such as liver cirrhosis, kidney disease, or congestive heart disease, all resulting in an increase in total body water (Dineen et al. 2017). These conditions may occur more frequently in psychiatric patients (Yip et al. 2020) or result in an increased risk of comorbid mental illness (Palmer et al. 2013). Moreover, and with particular relevance to psychiatric patients, hypervolemic $\mathrm{HN}$ can be caused by polydipsia, a condition which is most likely to occur in patients with schizophrenia (Dundas et al. 2007). Euvolemic HN is most often caused by the "syndrome of inappropriate ADH secretion" (SIADH) which is characterized by an increased release of ADH from the pituitary gland in absence of an appropriate stimulus. Among other possible causes such as pulmonary or malignant diseases, SIADH can be induced by drugs that chemically stimulate ADH secretion in the pituitary gland (Dineen et al. 2017).

Drug-induced HN is most commonly caused by DIUs, or more specifically, thiazide or thiazide-like diuretics (Liamis et al. 2008). While DIUs directly affect water and sodium homeostasis and result in renal loss of sodium, other drugs induce $\mathrm{HN}$ via one of three possible mechanisms: (1) central increase of $\mathrm{ADH}$-secretion, (2) potentiation of the effects of endogenous $\mathrm{ADH}$, or (3) lowering of the threshold for ADH secretion. Most psychotropic drugs associated with $\mathrm{HN}$ are believed to do so by inducing SIADH. A number of antidepressant drugs [ADDs, i.e., selective serotonin reuptake inhibitors (SSRIs), monoamine oxidase inhibitors
(MAOIs), tricyclic antidepressants (TCAs)], antipsychotic drugs (APDs), and antiepileptic drugs (AEDs) are ascribed a certain risk for inducing HN (Liamis et al. 2008; Meulendijks et al. 2010; Falhammar et al. 2019a).

The present study aims to assess the risk of specific psychotropic drugs and drug combinations of inducing HN by using data from a 24-year timeframe collected by a large pharmacovigilance program. This study serves as an update to a previous publication by Letmaier et al. 2012 which analyzed 93 cases of $\mathrm{HN}$ detected during the time period 1993-2007.

\section{Methods}

\section{The AMSP program}

Founded in 1993, AMSP (German: "Arzneimittelsicherheit in der Psychiatrie", "drug safety in psychiatry") is an on-going pharmacovigilance program in German-speaking countries, which collects data on unusual and severe adverse drug reactions (ADRs) affecting all organ systems (e.g., psychiatric, neurological, cardiovascular) to psychotropic drugs occurring during inpatient treatment.

An ADR is considered severe if,

- it is (potentially) life-threatening or seriously endangers a patient's health,

- it causes considerable impairment of everyday functioning, or

- it makes a transfer to another ward or department necessary for more specialized care (Grohmann et al. 2004, 2014).

The AMSP protocol provides additional guidelines based on each organ system to further standardize classification (Grohmann et al. 2014).

\section{Assessment and collection of ADRs}

Data collection is performed by psychiatrists, who have been appointed as drug monitors. ADRs are either spontaneously reported by treating physicians or come to attention during questioning of treating physicians by drug monitors in regular intervals (i.e., at least bi-weekly) and are then documented on a standardized questionnaire. Information including age, sex, somatic and psychiatric diagnoses, all medication taken at the time of the ADR, as well as an exact description of the ADR including any relevant diagnostic procedures, are gathered. Each ADR is also assessed for risk factors specific to the patient, possible alternative explanations, previous occurrence of the same ADR, course of the ADR, and measures taken to 
counteract the ADR. A senior physician of the hospital then re-examines each documented ADR for plausibility. Selected cases of ADRs are presented and discussed at regional and national case conferences which are attended by drug monitors of participating hospitals, representatives of the national drug regulating authorities, and experts in drug safety. The probability of causal relationship between an adverse event and the drug(s) imputed is determined as follows:

Grade 1: possible (ADR unknown or alternative explanation more likely)

Grade 2: probable (ADR known for drug imputed and course of time and dose in accordance with previous experience; alternative explanation less likely) Grade 3: definite (same as 2 with re-occurence of the ADR after re-exposure with the drug imputed)

Grade 4: questionable or not sufficiently documented.

More than one drug can be imputed for causing the ADR in question. In the case of $\mathrm{HN}$, this can be either due to additive effects of the other drug(s) in causing SIADH or as a result of the direct action of a second drug on sodium homeostasis via mechanisms other than SIADH. When multiple drugs are held responsible for an ADR, the causal relationship of each drug is graded individually. In turn, AMSP distinguishes between three subgroups of ADR cases: cases in which only one drug was imputed, cases in which a combination of drugs was imputed, and 'all cases' which includes both of the previously mentioned cases (Grohmann et al. 2004).

In this study, all events of HN recorded by AMSP between 1993 and 2016 in which at least one psychotropic drug was imputed as 'probable' or 'definite' cause of $\mathrm{HN}$ are included. According to the different risk of $\mathrm{HN}$ of involved drugs observed in a prior evaluation of HN occurring during treatment with psychotropic drugs (Letmaier et al. 2012), causality was assessed as follows: SSRIs, selective serotonin-norepinephrine reuptake inhibitors (SSNRIs), TCAs, the two AEDs carbamazepine and oxcarbazepine, angiotensin II receptor blockers (ARBs), angiotensin-converting-enzyme inhibitors (ACE-Is), DIUs, proton pump inhibitors originally associated with hyponatremia (PPIHNs), and proton pump inhibitors not originally associated with hyponatremia (PPINNs) were imputed as probable whenever present; APDs, as well as MAOIs, mirtazapine, trazodone, and valproate, were imputed as only 'possible' contributors to HN, if no clear evidence for a 'probable' role (most relevant for this assessment was temporal relationship) was present as $\mathrm{HN}$ is a rare event under treatment with these drugs.

\section{Classification of psychotropic and non-psychotropic drugs}

In the following, only psychotropic and non-psychotropic drugs involved in at least one case of $\mathrm{HN}$ are listed. Psychotropic drugs relevant to this study were classified as ADDs, APDs, and AEDs. ADDs were further classified as follows:

- SSRI: escitalopram, citalopram, sertraline, paroxetine, fluoxetine

- SSNRI: venlafaxine, duloxetine, milnacipran

- TCA: trimipramine, amitriptyline, doxepin

- Noradrenergic and specific serotonergic antidepressant (NaSSA): mirtazapine

- MAOI: tranylcypromine, moclobemide

- "other ADDs": agomelatine, reboxetine, trazodone, vortioxetine

APDs were classified as "first generation antipsychotic drugs" (FGAs) or "second generation antipsychotic drugs" (SGAs). FGAs were sub-classified as "low potency" (lp) or "high potency" (hp).

- lp FGA: prothipendyl, melperone

- hp FGA: haloperidol, perazine, flupentixol, zuclopenthixol

- SGA: quetiapine, olanzapine, risperidone, aripiprazole, paliperidone palmitate

AEDs included carbamazepine, oxcarbazepine, and valproic acid.

Non-psychotropic drugs were classified as follows:

- ACE-I: ramipril, enalapril, quinapril, lisinopril, clizapril, captopril, imidapril

- ARB: valsartan, candesartan, olmesartan, losartan, irbesartan, telmisartan

- DIU: torasemide, hydrochlorothiazide, furosemide, amiloride, xipamide, triamterene, spironolactone, indapamide

- PPIHN: omeprazole, esomeprazole, lansoprazole

- PPINN: pantoprazole

\section{Demographic, illness-related, and drug use data}

Data on drug use is gathered on two reference days per year on which all participating hospitals document all drugs prescribed on these days including exact dose, age, sex, psychiatric and somatic diagnoses. This information as well as a number of patients monitored each year and mean duration of inpatient stay allows an estimation of how many patients were exposed to a certain drug or combination of drugs. All obtained data is fully anonymized. 


\section{Definition and categorization of $\mathrm{HN}$}

AMSP defines severe $\mathrm{HN}$ as a $\mathrm{Na}(\mathrm{S})<130 \mathrm{mmol} / \mathrm{l}$ (Grohmann et al. 2004). As the collection of ADRs within the AMSP program is limited to severe ADRs and a $\mathrm{Na}(\mathrm{S})$ between 135 and 130 is defined as 'mild' and usually of lower clinical relevance (Spasovski et al. 2014), the $\mathrm{Na}(\mathrm{S})$ of $<130 \mathrm{mmol} / \mathrm{l}$ in this study is lower than the general definition of $\mathrm{HN}$ as determined by other studies (Mannesse et al. 2013; Mazhar et al. 2021). Cases with $\mathrm{Na}(\mathrm{S}) \geq 130 \mathrm{mmol} / \mathrm{l}$ were not eligible for inclusion. The following data only includes cases of $\mathrm{HN}$ in which the causal relationship of the drug was rated grade 2 or 3 . In this study, each ADR presenting with HN was categorized according to severity of symptoms (Spasovski et al. 2014; Bullmann 2016):

(0) Absence of symptoms

(1) Mild symptoms: imbalance, slight confusion, lethargy, fatigue, edema, vertigo, paresthesia, loss of appetite

(2) Moderately severe symptoms: headache, nausea without vomiting, confusion

(3) Severe symptoms: vomiting, cardiorespiratory distress, seizures, delirium, coma, somnolence

\section{Statistical methods}

Statistical analysis was performed using Excel $^{\odot}$. Overall incidence of $\mathrm{HN}$ is given in percent and $95 \%$ confidence intervall $(95 \% \mathrm{CI})$ of patients exposed to a specific drug, drug combination, drug class, or drug subclass. Because of the low actual incidence of $\mathrm{HN}$ and high overall exposure, the 95\% CI was calculated using the exact method (Vollset 1993). Fisher's exact tests were used to determine the significance of deviation between various drugs and drug combinations. A student's t-test was used to compare the means of two groups. The level of significance was set at $p<0.05$.

Risk of HN during polypharmacy/concomitant drug use-Risk of HN under treatment with certain drug/drug class combinations (i.e., SSRIs, SSNRIs, carbamazepine) was analyzed for specific drug combinations in which the psychotropic drug/drug class showed sufficiently high rates of $\mathrm{HN}$ both when imputed alone as well as in combination with other drugs. SSNRIs and SSRIs were subsumed as a group - the two SSNRIs venlafaxine and duloxetine both had similar rates of $\mathrm{HN}$, whereas a class-effect has been described for SSRIs (Egger et al. 2006; De Picker et al. 2014). Further, carbamazepine as an individual drug was selected because, though chemically related to oxcarbazepine, the two AEDs show significantly different risks of HN (more than tenfold). Clinically relevant drug combinations were determined according to the number of patients treated with the respective drug combination (i.e., $\geq 1,900$ patients) as drug combinations used in $<1,900$ patients resulted in increasingly wider $95 \%$ CIs limiting our ability to draw valid conclusions. Due to the insufficient number of patients treated with oxcarbazepine in combination with other drugs, drug combinations with oxcarbazepine are not further analyzed.

Risk of HN according to age and sex-SSRIs and SSNRIs were selected for analysis according to age and sex because they were the drug classes most commonly used both in the treatment of patients $<65$ and $\geq 65$ years of age. The analysis of other drugs/drug groups (e.g., carbamazepine) in this manner resulted in very wide, and therefore imprecise, $95 \%$ CIs.

\section{Ethics review}

Analyses using the AMSP database have been approved by the Ethics Committee of the University of Munich and the Ethics Committee of the Hannover Medical School (Nr. 8100_BO_S_2018). This study adheres to the Declaration of Helsinki and its later amendments. The AMSP programme is a continuous observational post-marketing drug surveillance programme and does not interfere with the ongoing clinical treatment of the patients under surveillance.

\section{Results}

\section{Demographic and illness-related data}

A total of 495,615 psychiatric inpatients were monitored within the hospitals participating in the AMSP project between 1993 and 2016. 93.4\% of patients $(462,661$ patients) were treated with at least one psychotropic drug. A total of 210 cases of $\mathrm{HN}$ affecting $0.05 \%$ of patients treated with psychotropic drugs were documented during this time period that fulfilled AMSP's criteria. Females were affected in 156 (74.3\%) of cases. While patients aged $\geq 65$ years constituted about a fifth of the total study population, nearly half of patients with $\mathrm{HN}$ were $\geq 65$ years of age indicating that patients within this age group were nearly 3 times more likely to develop HN than younger patients $(<65$ years; $0.104 \%$ vs. $0.290 \%, p<0.001$ ). More than half (i.e., $58.1 \%$ ) of patients with drug-induced HN suffered from mood disorders (ICD-10: F3). Patients suffering from substance-related disorders (ICD-10: F1) presented the highest incidence $(0.111 \%$ of patients within this subgroup) of HN within diagnostic subgroups (Table 1).

\section{Serum sodium concentration and symptom presentation}

Most frequently patients presented without any clinical manifestations of $\mathrm{HN}$ (57.1\%); $19.0 \%$ showed severe symptoms 
Table 1 Characteristics of the study population

\begin{tabular}{|c|c|c|c|c|}
\hline & $\begin{array}{l}\text { All patients monitored, } \\
\mathrm{N} \text { (\% of } 462,661 \text { patients) }\end{array}$ & $\begin{array}{l}\text { Patients with } \mathrm{HN}, \\
\mathrm{N}(\% \text { of } 210 \text { patients) }\end{array}$ & $\begin{array}{l}\% \text { of patients } \\
\text { with HN }\end{array}$ & $p$ value \\
\hline All patients & $462,661(100)$ & $210(100)$ & 0.05 & \\
\hline \multicolumn{5}{|l|}{ Diagnosis (ICD-10) } \\
\hline Organic disorders (F0) & $56,419(12.2)$ & $19(9.0)$ & 0.034 & \multirow{5}{*}{$\begin{array}{l}\chi^{2}=74.651 ; \mathrm{df}=4 \\
p<0.001 *\end{array}$} \\
\hline Substance-related disorders (F1) & $20,637(4.5)$ & $23(11.0)$ & 0.111 & \\
\hline Schizophrenia (F2) & $158,037(34.2)$ & $30(14.3)$ & 0.019 & \\
\hline Mood disorders (F3) & $171,165(37.0)$ & $122(58.1)$ & 0.010 & \\
\hline Others (F4-F9) & $56,403(12.1)$ & $16(7.6)$ & 0.028 & \\
\hline \multicolumn{5}{|c|}{ Age of patients treated with psychotropic drugs } \\
\hline$<65$ years & $363,562(78.6)$ & $107(51.0)$ & 0.029 & \multirow{2}{*}{$\begin{array}{l}\chi^{2}=95.153 ; \mathrm{df}=1 \\
p<0.001 *\end{array}$} \\
\hline$\geq 65$ years & $99,099(21.4)$ & $103(49.0)$ & 0.104 & \\
\hline \multicolumn{5}{|l|}{ Sex } \\
\hline Male & 204,071 (44.1) & $54(25.7)$ & 0.026 & \multirow{2}{*}{$\begin{array}{l}\chi^{2}=28.808 ; \mathrm{df}=1 ; \\
p<0.001 *\end{array}$} \\
\hline Female & $258,590(55.9)$ & $156(74.3)$ & 0.060 & \\
\hline
\end{tabular}

$N$ number, $H N$ hyponatremia, $d f$ degrees of freedom, $I C D$ - 10 International Classification of Disease, 10th Version

*statistically significant

(Table 2). The mean ( \pm standard deviation) $\mathrm{Na}(\mathrm{S})$ among all patients with drug-induced $\mathrm{HN}$ was $120.5 \pm 6.0 \mathrm{mmol} / \mathrm{l}$ (range 102.0-129.0 mmol/1, median $119.0 \mathrm{mmol} / \mathrm{l}$ ). Patients presenting without any symptoms had higher $\mathrm{Na}(\mathrm{S})$ $(123.0 \pm 4.3 \mathrm{mmol} / \mathrm{l})$ than patients suffering from mild to severe symptoms $(117.0 \pm 6.1 \mathrm{mmol} / \mathrm{l} ; p<0.001)$. Na(S) differed significantly between cases of moderate HN compared to severe HN ( $p=0.006)$, while this was not the case for the comparison of moderate HN compared to mild symptomatic HN $(p>0.05)$. Table 2 also shows the mean and median $\mathrm{Na}(\mathrm{S})$ in correlation to clinical symptoms as well as several symptoms of severe HN (e.g., seizures, delirium, vomiting, falls, somnolence, coma). In cases of severe $\mathrm{HN}, \mathrm{Na}(\mathrm{S})$ ranged from a minimum of $102.0 \mathrm{mmol} / \mathrm{l}$ to $128.0 \mathrm{mmol} / \mathrm{l}$. Of note, $\mathrm{Na}(\mathrm{S})$ was only mildly lowered (i.e., $125.0 \mathrm{mmol} / \mathrm{l}$ ) in some cases presenting with severe symptoms, while on the other hand, cases with a minimum $\mathrm{Na}(\mathrm{S})$ of $109.0 \mathrm{mmol} / \mathrm{l}$ did not show any clinical symptoms.

\section{Psychotropic drugs associated with HN}

HN was caused by a single psychotropic drug in only 61 cases $(29.0 \%)$. The majority (i.e., $71.0 \%$ ) of cases were caused by more than one (psychotropic) drug. Table 3 shows the psychotropic drug classes/drugs involved in HN. Unless
Table 2 Clinical presentation of drug-induced hyponatremia according to severity, symptoms, and serum sodium concentration

\begin{tabular}{lllll}
\hline Clinical presentation of $\mathrm{HN}$ & $\begin{array}{l}\text { Number of cases } \\
(\%)\end{array}$ & $\begin{array}{l}\text { Mean Na(S) } \pm \mathrm{SD} \\
\text { (in mmol/l) }\end{array}$ & $\begin{array}{l}\text { Median Na(S) } \\
\text { in mmol/l }\end{array}$ & $\begin{array}{l}\text { Range; } \\
\text { Min-Max } \\
\text { (in mmol/l) }\end{array}$ \\
\hline All cases & $210(100)$ & $120.5 \pm 5.6$ & 119.0 & $102-129$ \\
Asymptomatic & $120(57.1)$ & $123.0 \pm 4.3$ & 124.0 & $109-129$ \\
All symptomatic cases & $90(42.9)$ & $117.0 \pm 6.1$ & 118.0 & $102-129$ \\
Mild symptoms & $23(11.0)$ & $121.6 \pm 4.1$ & 122.0 & $117-128$ \\
Moderately severe symptoms & $22(10.5)$ & $119.4 \pm 4.8$ & 118.5 & $111-129$ \\
Severe symptoms & $40(19.0)$ & $115.4 \pm 6.2$ & 116.0 & $102-128$ \\
Seizures & 16 & $115.1 \pm 6.1$ & 114.5 & $104-123$ \\
Delirium & 17 & $115.2 \pm 5.5$ & 116.0 & $104-123$ \\
Vomiting & 14 & $114.5 \pm 6.2$ & 116.5 & $102-125$ \\
Falls & 14 & $114.5 \pm 6.5$ & 116.5 & $102-125$ \\
Somnolence & 8 & $113.1 \pm 6.1$ & 114.5 & $102-120$ \\
Coma & 2 & $104.0 \pm 0$ & 104.0 & 104 \\
\hline
\end{tabular}

$H N$ hyponatremia; $\mathrm{Na}(\mathrm{S})$ : serum sodium concentration; $S D$ : standard deviation; min: minimum; max: maximum 
Table 3 Incidence of drug-induced hyponatremia among psychotropic drugs and drug classes

\begin{tabular}{|c|c|c|c|c|c|}
\hline Drug class/drug & $\mathrm{N}$ patients exposed & $\begin{array}{l}\mathrm{N} \text { patients with } \mathrm{HN} \text { (all } \\
\text { imputations) }\end{array}$ & $\begin{array}{l}\mathrm{N} \text { cases of } \mathrm{HN} \text { with } \\
\text { single imputation }\end{array}$ & $\begin{array}{l}\% \text { of patients with } \mathrm{HN} \text { (all } \\
\text { imputations) }\end{array}$ & $95 \% \mathrm{CI}$ \\
\hline \multicolumn{6}{|l|}{ Antidepressant drugs } \\
\hline Any ADD & 243,588 & 124 & 23 & 0.051 & $0.042-0.061$ \\
\hline SSRI & 92,496 & 66 & 15 & 0.071 & $0.055-0.091$ \\
\hline Citalopram & 24,904 & 30 & 6 & 0.120 & $0.081-0.172$ \\
\hline Escitalopram & 25,667 & 17 & 3 & 0.066 & $0.039-0.106$ \\
\hline Sertraline & 21,868 & 15 & 5 & 0.069 & $0.038-0.113$ \\
\hline Paroxetine & 10,298 & 3 & 1 & 0.029 & $0.008-0.065$ \\
\hline Fluoxetine & 5849 & 1 & 0 & 0.172 & $0.000-0.095$ \\
\hline SSNRI & 56,530 & 50 & 4 & 0.088 & $0.066-0.123$ \\
\hline Venlafaxine & 41,559 & 37 & 2 & 0.089 & $0.063-0.123$ \\
\hline Duloxetine & 14,343 & 12 & 2 & 0.084 & $0.043-0.146$ \\
\hline Milnacipran & 858 & 1 & 0 & 0.117 & $0.003-0.648$ \\
\hline NaSSA & 63,182 & 1 & 0 & 0.002 & $0.003-0.021$ \\
\hline Mirtazapine & 60,305 & 1 & 0 & 0.002 & $0.000-0.009$ \\
\hline TCA & 56,666 & 9 & 4 & 0.016 & $0.007-0.030$ \\
\hline Amitriptyline & 14,089 & 6 & 3 & 0.043 & $0.016-0.093$ \\
\hline Clomipramine & 6174 & 2 & 0 & 0.032 & $0.004-0.117$ \\
\hline Trimipramine & 13,604 & 1 & 1 & 0.007 & $0.000-0.041$ \\
\hline MAOI & 4855 & 2 & 0 & 0.041 & $0.005-0.149$ \\
\hline Tranylcypromine & 2384 & 1 & 0 & 0.042 & $0.001-0.233$ \\
\hline Moclobemide & 2471 & 1 & 0 & 0.040 & $0.001-0.225$ \\
\hline other ADDs & 24,761 & 5 & 0 & 0.020 & $0.007-0.047$ \\
\hline Trazodone & 12,571 & 4 & 0 & 0.032 & $0.009-0.081$ \\
\hline Vortioxetine & 501 & 1 & 0 & 0.200 & $0.005-1.107$ \\
\hline \multicolumn{6}{|l|}{ Antiepileptic drugs } \\
\hline any AED & 99,846 & 89 & 35 & 0.089 & $0.072-0.110$ \\
\hline Carbamazepine & 24,308 & 41 & 15 & 0.169 & $0.121-0.229$ \\
\hline Oxcarbazepine & 2710 & 45 & 19 & 1.661 & $1.214-2.216$ \\
\hline Valproic acid & 42,259 & 7 & 1 & 0.017 & $0.007-0.034$ \\
\hline \multicolumn{6}{|l|}{ Antipsychotic drugs } \\
\hline any APD & 333,175 & 16 & 3 & 0.005 & $0.003-0.008$ \\
\hline hp FGA & 92,980 & 6 & 0 & 0.006 & $0.002-0.014$ \\
\hline Haloperidol & 37,650 & 3 & 0 & 0.008 & $0.002-0.023$ \\
\hline Perazine & 15,495 & 2 & 2 & 0.013 & $0.002-0.047$ \\
\hline Zuclopenthixol & 7144 & 1 & 0 & 0.014 & $0.000-0.078$ \\
\hline lp FGA & 102,468 & 2 & 0 & 0.002 & $0.000-0.007$ \\
\hline Melperone & 18,984 & 1 & 0 & 0.005 & $0.000-0.029$ \\
\hline Prothipendyl & 15,742 & 1 & 0 & 0.006 & $0.000-0.035$ \\
\hline SGA & 226,161 & 11 & 1 & 0.005 & $0.002-0.009$ \\
\hline Olanzapine & 54,822 & 2 & 0 & 0.004 & $0.000-0.013$ \\
\hline Quetiapine & 66,209 & 3 & 0 & 0.005 & $0.001-0.013$ \\
\hline Aripiprazole & 15,988 & 1 & 0 & 0.006 & $0.000-0.035$ \\
\hline Risperidone & 51,683 & 5 & 0 & 0.010 & $0.003-0.023$ \\
\hline Paliperidone palmitate & 1279 & 1 & 1 & 0.078 & $0.002-0.435$ \\
\hline
\end{tabular}

This table only includes cases in which the psychotropic drug was considered a 'probable' or 'definite' cause of HN; 'possible' causality is not included. Psychotropic drugs never imputed in HN were benperidol, bromperidol, haloperidol decanoate, flupentixol, fluphenazine, pipamperone, flupentixol, chlorprothixene, zotepine, clotiapine, ziprasidone, sertindole, levomepromazine, perphenazine, promethazine, promazine, amisulpride, agomelatine, mianserin, maprotiline, nefazodone, reboxetine, imipramine, nortriptyline, doxepin, bupropion, fluvoxamine, topiramate, opipramol, diazepam, lorazepam, zopiclone, zolpidem, chloral hydrate, clomethiazole, pregabalin, lamotrigine, biperiden, memantine, donepezil, galantamine, rivastigmine, and methylphenidate.

$N$ number, $H N$ hyponatremia, 95\% CI 95\% confidence interval, $A D D$ antidepressant drug, $A P D$ antipsychotic drug, AED antiepileptic drug, TCA tricyclic antidepressant, SSRI selective serotonin reuptake inhibitor, SSNRI selective serotonin-norepinephrine reuptake inhibitor, NaSSA noradrenergic and specific serotonergic antidepressant, MAOI monoamine oxidase inhibitor, FGA first generation antipsychotic drug, $S G A$ second generation antipsychotic drug, $h p$ high potency, $l p$ low potency 
explicitly stated otherwise, the following refers to all cases of HN (i.e., multiple and single imputations).

Antidepressant drugs: out of all cases of HN, ADDs were the psychotropic drug class most commonly imputed in psychotropic drug-induced HN (124 cases, $59.0 \%$ of HN cases) $-0.051 \%$ of patients treated with ADDs developed HN. SSNRIs were the ADD-subgroup with the highest risk of $\mathrm{HN}$ affecting $0.088 \%$ of SSNRI-users, while citalopram was the individual drug most commonly associated with HN $(0.120 \%$ of patients exposed). Only a single probable case was observed with the imputation of NaSSAs, therefore resulting in the lowest risk of HN among ADDs. In about one-fifth of cases (23 cases of HN, 18.5\% of ADD-induced $\mathrm{HN}$ ), an ADD was imputed alone for causing HN-SSRIs in 15 , SSNRIs in 4 , and TCAs in 4 cases; MAOIs and NaSSAs were never imputed alone.

Antiepileptic drugs: AEDs were imputed in 89 cases of $\mathrm{HN}$ (42.4\% of HN cases) and were the psychotropic drug class with the highest incidence of $\mathrm{HN}(0.089 \%$ of patients exposed) and also most likely to be imputed alone (35 cases, 39.3\% of AED-induced HN). Oxcarbazepine showed the by far highest risk of $\mathrm{HN}$ affecting $1.661 \%$ of patients treated. Oxcarbazepine was imputed alone in 19 cases of HN (1.59\% of patients treated with oxcarbazepine alone; 95\% CI 0.96-2.48; data not shown). Carbamazepine showed the second highest risk of $\mathrm{HN}$ among all psychotropic drugs $(0.169 \%)$.

Antipsychotic drugs: in relation to the high number of exposed patients, APDs were only very rarely associated as 'probable' or 'definite' cause of HN. Overall, 16 such cases of APD-induced $\mathrm{HN}$ were detected $(7.6 \%$ of $\mathrm{HN}$ cases) of which 4 occurred without imputation of other drugs under treatment with perazine ( 2 cases), paliperidone palmitate ( 1 case), and a combination of 3 APDs (zuclopenthixol+ aripiprazole + risperidone). Including the cases with "possible' imputations of an APD, the risk of drug-induced HN remained low (single and multiple imputation: 115 cases, $0.03 \%$; imputed alone: 6 cases, $0.002 \%$; data not shown in tables/figures).

\section{Dose-dependent effects of HN}

Among cases of $\mathrm{HN}$ in which a single drug was imputed, dose-dependent effects were found exclusively for oxcarbazepine (mean dose of all patients exposed $\left(\mathrm{MD}_{\mathrm{all}}\right)$ : $865.0 \pm 482.0 \mathrm{mg}$ vs. mean dose of patients with HN $\left.\left(\mathrm{MD}_{\mathrm{HN}}\right): 1129.0 \pm 436.3 ; p=0.017\right)$.

When imputed alone, SSRIs and SSNRIs did not exhibit dose-dependency. However, when considering all cases of $\mathrm{HN}$ including multiple imputations, mean dosage of several drugs was significantly lower in patients who experienced $\mathrm{HN}$ compared to all patients exposed. This was observed for sertraline $\left(\mathrm{MD}_{\text {all }}: 98.0 \pm 56.7 \mathrm{mg}\right.$ vs. $\mathrm{MD}_{\mathrm{HN}}: 64.3 \pm 37.1 \mathrm{mg}$; $p=0.021)$, venlafaxine $\left(\mathrm{MD}_{\mathrm{all}}: 190.8 \pm 85.4\right.$ vs. $\mathrm{MD}_{\mathrm{HN}}$ : $137.2 \pm 59.6 \mathrm{mg} ; p<0.001)$, and duloxetine $\left(\mathrm{MD}_{\mathrm{all}}\right.$ : $80.7 \pm 38.9 \mathrm{mg}$ vs. $\left.\mathrm{MD}_{\mathrm{HN}}: 52.5 \pm 21.7 \mathrm{mg} ; p=0.001\right)$.

\section{Polypharmacy and concomitant drug use}

Figure 1 shows the most common combinations of psychotropic drug groups and individual drugs (i.e., SSRIs, SSNRIs, carbamazepine) with other $\mathrm{HN}$-inducing drugs involved in HN. Risk of HN increased when the respective psychotropic drug class or drug was combined with other potentially $\mathrm{HN}$-inducing drugs used to treat internal illnesses such as ACE-Is, ARBs, DIUs, PPIHNs, and PPINNs. For example, when combined with a DIU or ACE-I, SSRI-users had a tenfold higher risk of developing $\mathrm{HN}$ than those treated without DIUs or ACE-Is. The risk of HN increased further when an SSRI-user was treated with both a DIU and an ACE-I. The same was observed among SSNRI-users. Similarly, the risk of $\mathrm{HN}$ increased among carbamazepine-users when used in combination with DIUs, ACE-Is, or PPINNs. It must be noted that confidence intervals-especially of drug combinations - are often wide and overlapping, therefore, disabling precise estimations.

The concomitant use of any PPI was also associated with a higher incidence of $\mathrm{HN}$ - concomitant use of a PPIHN was more likely to induce HN than the use of PPINNs. In fact, when used in combination with a PPIHN, patients treated with SSRIs and SSNRIs were more than twice as likely to develop HN than when these drugs were used with the PPINN pantoprazole.

The risk of HN did not significantly increase when SSRIs or SSNRIs were used in combination with an APD. Even when all cases with a 'possible' co-imputation of APDs were included in the analysis, incidence was comparable to that of ADDs $(0.01 \%, 95 \%$ CI $0.01-0.02$ for ADD + APD; data not shown), SSRIs $(0.02 \%, 95 \%$ CI $0.01-0.03$ for SSRI + APD, Fig. 1), or SSNRIs (0.02\%, 95\% CI 0.00-0.05 for SSNRI + APD, Fig. 1) when imputed alone.

A combination of drugs was imputed in 36 of the HN cases with severe symptoms detected in this study. A single psychotropic drug was imputed alone in only 4 cases (one case each under treatment with oxcarbazepine, carbamazepine, sertraline, and citalopram; data not shown in tables/ figures).

\section{Polypharmacy and concomitant drug use according to gender and age}

Figure 2 shows frequencies of HN in SSRI- and SSNRIusers according to gender and age. Female SSNRI-users aged $\geq 65$ years concomitantly using other $\mathrm{HN}$-inducing drugs were the subgroup with the highest risk of developing $\mathrm{HN}-0.68 \%$ (95\% CI $0.47-0.95$ ) of patients within 


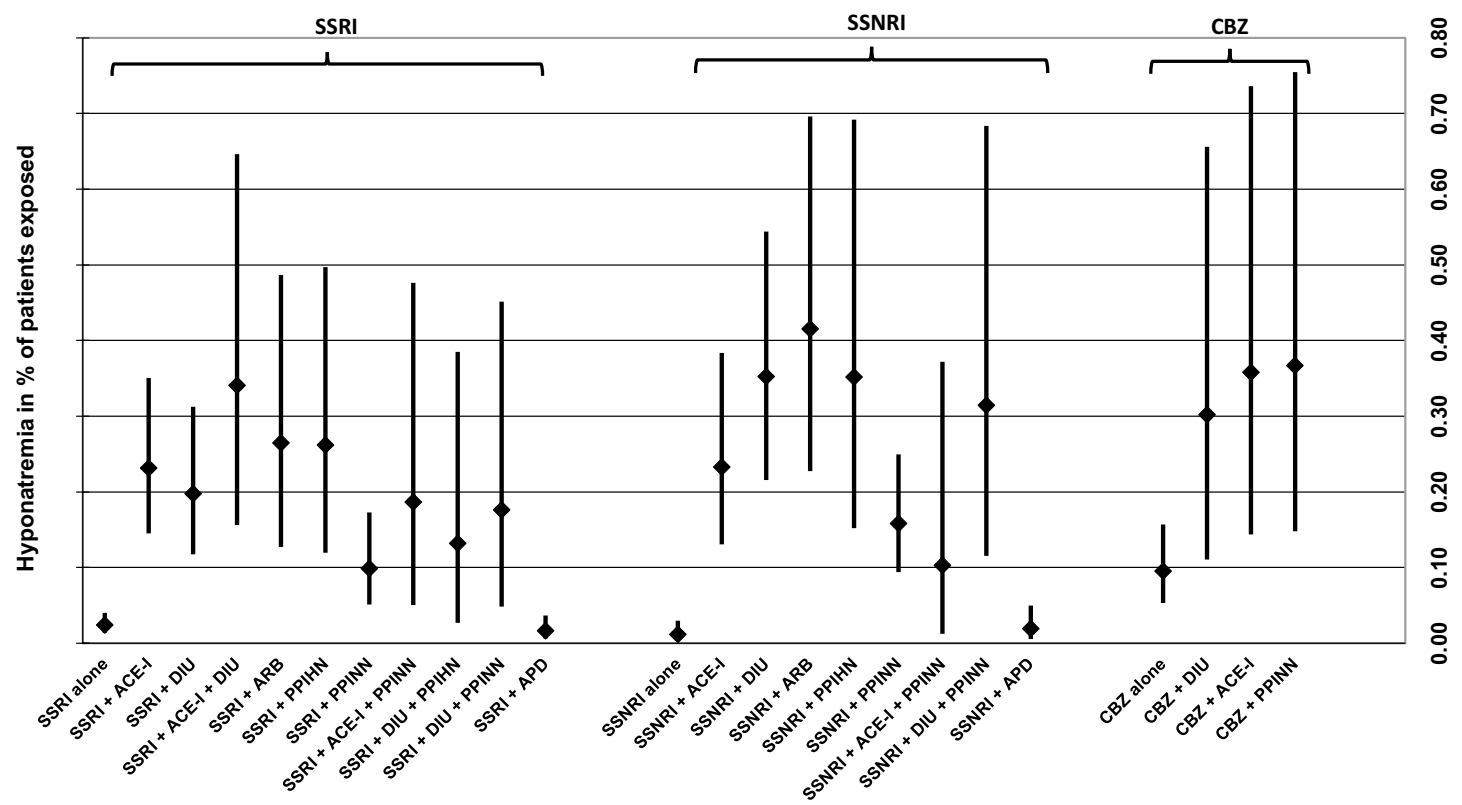

0
0
0
0
0
0
0
0
0
0
0
0
0
0
0
0
0
0
0
0
0
0
0
0

Fig. 1 Incidence of hyponatremia including 95\% CI of SSRIs, SSNRIs, and CBZ alone and in combination with other drugs. Only drug combinations used in $\geq 1900$ patients are depicted. 95\% CI 95\% confidence interval, SSRI selective serotonin reuptake inhibitor, SSNRI selective serotonin-norepinephrine reuptake inhibitor, CBZ carba-

this group developed HN. The risk of HN was significantly higher among this patient subgroup when compared to males of the same age group $(p=0.02)$. With confidence intervals overlapping among the other age and sex groups of SSRIand SSNRI-users, no such marked differences between cases in which an SSRI/SSNRI was imputed alone vs. SSRI/ SSNRI was imputed in combination with other drugs was detected.

\section{Time to onset of HN}

In cases in which a single psychotropic drug was imputed, HN occurred after a median of 7 days (range 1-2111 days; interquartile range 15.5 days) after initiation of the imputed drug or increase of dosage. In 40 cases $(64.5 \%)$, dosage of the imputed psychotropic drug had been increased prior to the detection of HN. When imputed alone, HN occurred within 3 weeks in $87 \%$ of cases imputing SSRIs, in $75 \%$ of cases imputing SSNRIs, in $66 \%$ of cases imputing carbamazepine, and in $83 \%$ of cases imputing oxcarbazepine.

When multiple drugs were held responsible for $\mathrm{HN}$, SSRIs, SSNRIs, carbamazepine, and oxcarbazepine had been used for $\leq 3$ weeks in more than $50 \%$ of cases. The coimputed non-psychotropic drugs had been used for a longer period of time in a majority of cases (i.e., for more than 3 weeks in about $2 / 3$ of co-imputations for PPIHNs, in $>80 \%$ for ACE-Is, ARBs, PPINNs, and DIUs, and for $>3$ months mazepine, APD antipsychotic drug, ACE-I angiotensin-convertingenzyme inhibitor, ARB angiotensin II receptor blocker, DIU diuretic drug, PPIHN proton pump inhibitor originally associated with hyponatremia, PPINN proton pump inhibitor not originally associated with hyponatremia

in 52\% of co-imputations of PPIHNs and $>63 \%$ of co-imputations of ACE-Is, ARBs, PPINNs, and DIUs).

\section{Risk factors}

In 153 cases (72.7\%), no risk factors for the occurrence of $\mathrm{HN}$ were identified. However, under consideration of patients with severe symptomatic HN (e.g., seizure, coma, delirium, somnolence; $n=40$ ), predisposing risk factors for $\mathrm{HN}$ or for the development of severe symptoms were identified in more than half of the patients affected ( 24 cases; $60.0 \%$ ) such as substance use disorders (6 cases), gastrointestinal disturbances prior to HN (i.e., vomiting/diarrhea; 4 cases), low $\mathrm{Na}(\mathrm{S})$ prior to drug initiation (4 cases), or polydipsia (3 cases). Among patients presenting with a seizure, 3 patients had experienced at least one previous seizure and 6 suffered from pre-existing brain damage.

\section{Countermeasures and course of HN}

In most cases, one or more of the imputed drugs was discontinued (184 cases; $87.6 \%$ ). Daily dose was reduced in 22 cases (10.4\%), while treatment was continued without any alteration in only a single case of asymptomatic $\mathrm{HN}$ $(0.5 \%) .49$ patients $(23.3 \%)$ required a transfer to an inter$\mathrm{nal} /$ neurological department or intensive care unit to receive more specialized care. Four cases resulted in life-threatening 


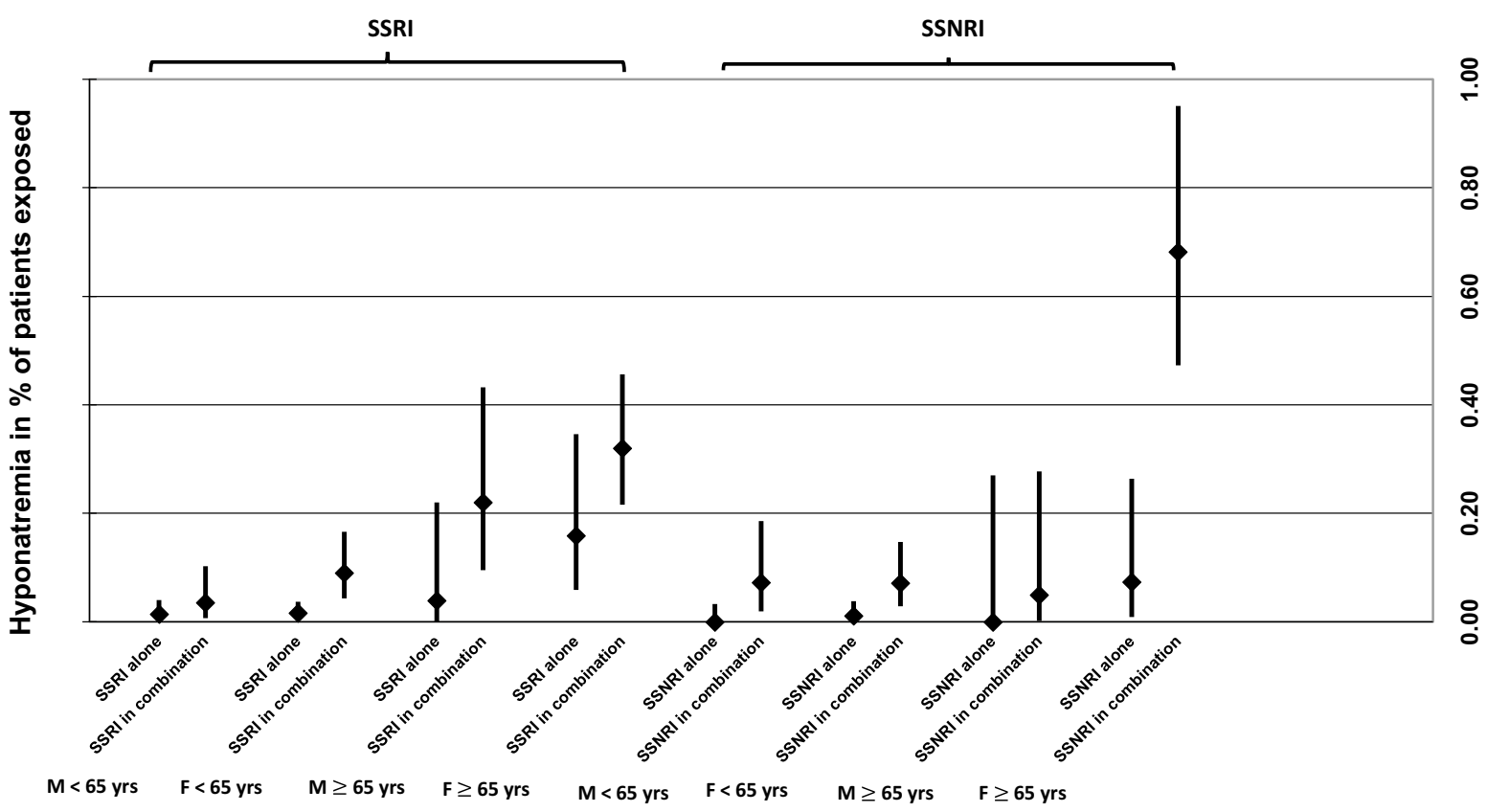

Fig. 2 Incidence of hyponatremia including 95\% CI for SSRI- and SSNRI-users according to sex, age, and concomitant drug use. 95\% CI 95\% confidence interval, $\mathrm{M}$ males, $\mathrm{F}$ females, Yrs years, SSRI

symptoms (i.e., cerebral edema-2 cases, aspiration pneumonia resulting from a seizure, and central pontine myelinolysis after rapid sodium substitution-1 case each).

Pharmacological countermeasures (i.e., intravenous hypertonic or isotonic saline, sodium tablets) were taken in 131 cases (62.4\%); non-pharmacological measures (i.e., high-sodium diet, fluid restriction) were taken in 40 cases $(19.0 \%)$.

At the end of the observation period, HN had fully subsided in a majority of cases (166 cases; $79.1 \%$ ) or was in the process of subsiding (30 cases; $14.3 \%$ ). In 11 cases $(5.2 \%)$, $\mathrm{HN}$ remained unchanged, while 1 case resulted in permanent damage following coma and intracranial hypertension $(0.5 \%)$. The course of HN was unknown in 2 cases $(1.0 \%)$.

\section{Discussion}

This study examined the incidence of HN occurring under treatment with psychotropic drugs. Oxcarbazepine was the psychotropic drug with the greatest risk of HN affecting $1.66 \%$ of patients treated, followed by carbamazepine, SSNRIs, and SSRIs. Combination treatments, especially with DIUs, ACE-Is, and ARBs, were found to significantly increase the risk of developing $\mathrm{HN}$ by up to a 40 -fold. A smaller number of cases of HN were associated with the use of other psychotropic drugs (i.e., mirtazapine, TCAs, and APDs). HN was detected a median of 7 days after initiation selective serotonin reuptake inhibitor, SSNRI selective serotonin-norepinephrine reuptake inhibitor

of treatment or increase of dosage of the imputed psychotropic drug.

\section{HN under treatment with psychotropic drugs}

Despite the high risk of HN reported by some authors (Strachan and Shepherd 1998), many cases of psychotropic-drug induced HN may present asymptomatically or with unspecific symptoms - as was the case in the present studywhich in turn may mean, that these cases remain unnoticed if $\mathrm{Na}(\mathrm{S})$ is not monitored regularly. This may have contributed to an under-reporting of HN in this study. Patients with 'asymptomatic' HN in this study presented with a mean $\mathrm{Na}(\mathrm{S})$ of $124 \mathrm{mmol} / \mathrm{l}$, a $\mathrm{Na}(\mathrm{S})$ generally expected to be associated with moderate to severe HN (Spasovski et al. 2014). As HN often presents with nonspecific symptoms such as lethargy, fatigue, and confusion, which can easily be mistaken for worsening of depressive symptoms, these cases may have wrongfully been deemed 'asymptomatic'. In the present study assessing only severe ADRs, HN was defined as $\mathrm{Na}(\mathrm{S})<130 \mathrm{mmol} / \mathrm{l}$ while other authors defined $\mathrm{HN}$ as $\mathrm{Na}(\mathrm{S})$ of $<135 \mathrm{mmol} / \mathrm{l}$. This discrepancy in definition may contribute to the wide range of frequencies of psychotropic drug-induced HN reported by other authors. Moreover, due to AMSP's strict criteria and the inclusion of cases only if $\mathrm{Na}(\mathrm{S})<130 \mathrm{mmol} / \mathrm{l}$, it is likely that many more patients suffered from $\mathrm{HN}$ as defined by other authors. 


\section{Antidepressant drugs}

An association between SSRIs and the occurrence of HN was first noted by Hwang and Magraw (1989) and has been described for all currently marketed SSRIs (Jacob and Spinler 2006). While ADD-induced HN is most commonly associated with the use of SSRIs and SSNRIs, it is not an ADR specific to these classes of ADDs (Wright and Schroeter 2008). In general, HN is a phenomenon which has been described to occur under the use of almost all ADDs (De Picker et al. 2014). TCAs and mirtazapine have shown a lower risk of HN in comparison to SSRIs or SSNRIs (Farmand et al. 2018), as was the case in the present study. A single case of $\mathrm{HN}$ with co-imputation of mirtazapine was documented by AMSP. Other authors disagree stating mirtazapine has a higher risk of causing HN than SSRIs and SSNRIs (Mazhar et al. 2019).

It is still unclear if any single SSRI has a higher risk of $\mathrm{HN}$ than the others so that in general a class-effect of SSRIs is postulated (Egger et al. 2006; De Picker et al. 2014). One study found that up to $24 \%$ of hospitalized patients treated with either of the two SSRIs paroxetine or fluoxetine developed $\mathrm{HN}$ at some point during hospitalization (Strachan and Shepherd 1998). While other SSRIs were not examined in the above-mentioned study, therefore impeding further comparisons to the present study, it is of note that paroxetine was found to have the lowest risk of HN among SSRIs in this study. Other studies agree with the present results that escitalopram and citalopram are associated with higher incidences of HN compared to other substances within the drug class (Degner et al. 2004; Coupland et al. 2011a, 2011b; Letmaier et al. 2012; Shepshelovich et al. 2017), whereas paroxetine seems to less frequently cause $\mathrm{HN}$ (Letmaier et al. 2012). This seemingly lower rate of paroxetine- and fluoxetine-induced $\mathrm{HN}$ may derive from a bias in the use of paroxetine and fluoxetine. Paroxetine is a potent inhibitor of the cytochrome $\mathrm{P} 450$ isoenzyme 2D6 potentially causing significant drug-drug interactions (Bahar et al. 2018) and therefore may show higher utilization among younger patients who are less likely to be treated with multiple drugs and less predisposed to develop HN. Similarly, as fluoxetine is the SSRI with the longest half-life, which may be even longer in older patients potentially resulting in an increased risk for drug-drug interactions (Ferguson and Hill 2006), use of fluoxetine may also be lower among older patients.

SSRIs cause serotonin levels to increase, which leads to the stimulation of 5- $\mathrm{HT}_{1 \mathrm{c}}$ and $5-\mathrm{HT}_{2}$ receptors in turn activating ADH secretion (Spigset and Hedenmalm 1995). Some authors have hypothesized that the risk of an ADD to cause HN correlates with the drugs' potency to inhibit the re-uptake of serotonin (Degner et al. 2004), which may in part explain the higher incidence of $\mathrm{HN}$ among users of citalopram and escitalopram. Further, it is postulated that norepinephrine stimulates the secretion of ADH (Knigge et al. 1999), providing a possible explanation for the slightly higher risk of HN under treatment with SSNRIs $(0.09 \%$; imputed alone and in combination) than with SSRIs (0.07\%) found in the present study. Overall, the incidence of $\mathrm{HN}$ among SSNRIs is less researched than among SSRIs. Studies examining the risk of $\mathrm{HN}$ under treatment with venlafaxine found risks equal to or higher than for SSRIs, while duloxetine is less examined (De Picker et al. 2014). The present study confirms these results.

\section{Antiepileptic drugs}

Several AEDs are attributed a high risk of inducing HN. Carbamazepine (Shepshelovich et al. 2017; Falhammar et al. 2018) and, even more frequently, oxcarbazepine have been found to be the AEDs most likely to cause HN (Liamis et al. 2008; Falhammar et al. 2018). In fact, HN has been described as the leading ADR in psychiatric inpatients during treatment with oxcarbazepine (Druschky et al. 2018). Intravooth et al. detected $\mathrm{HN}$ in $43 \%$ of oxcarbazepine-users and $33 \%$ of oxcarbazepine-users in a cohort consisting of 560 patients, though none of these cases were classified as severe (2018). The present study detected the highest incidence of $\mathrm{HN}$ in oxcarbazepine-users (1.66\%) in comparison to all other psychotropic drugs, followed by carbamazepine $(0.17 \%)$. Even when imputed alone, oxcarbazepine had a nearly 16 -fold higher risk of $\mathrm{HN}$ than carbamazepine and an almost 80-fold increased risk in comparison to SSRIs alone.

Further, this study detected 7 events of HN associated with the use of valproic acid. The risk of $\mathrm{HN}$ during treatment with other AEDs such as valproic acid (Druschky et al. 2018; Intravooth et al. 2018) or levetiracetam (Intravooth et al. 2018) are only rarely associated with the occurrence of HN. However, this study found valproic acid to have a comparable risk of $\mathrm{HN}(0.02 \%)$ as the SSRI paroxetine $(0.03 \%)$.

\section{Antipsychotic drugs}

The role of APDs in inducing HN is less conclusive than that of the above-mentioned drug groups (Meulendijks et al. 2010). First reports of HN occurring under treatment with APDs arose in the 1970s, when thiothixene (a thioxanthene derivate) (Ajlouni et al. 1974) and haloperidol (Peck and Shenkman 1979) were found to impair the patient's ability to excrete a free water load. Patients treated with FGAs appear to be more likely to experience HN than those treated with SGAs (Yang and Cheng 2017; Falhammar et al. 2019a). A recent case-control study demonstrated that the use of any FGA was more likely to cause hospitalization due to HN upon initiation of drug treatment in comparison to SGAs. When considering ongoing treatment, the risk of $\mathrm{HN}$ decreased for FGAs while it slightly increased 
for SGAs (Falhammar et al. 2019a). However, in comparison to non-users, SGA-users may have an increased risk of hospitalization due to HN (Gandhi et al. 2016). In many of the published reports of APD-induced HN, causality of the APD was deemed 'possible' and to a lesser extent 'probable'. There are, however, also reports of rechallenge and subsequent reoccurrence of $\mathrm{HN}$ for several APDs including haloperidol, quetiapine, and aripiprazole (Meulendijks et al. 2010).

The most recent study assessing the risk of $\mathrm{HN}$ under treatment with APDs examined the relationship between receptor occupancy of APDs and HN. While the degree of occupancy of dopamine D3 receptors positively correlated with the occurrence of $\mathrm{HN}$, a negative association was found for the occupancy of serotonin 5- $\mathrm{HT}_{2 \mathrm{~A}}$ receptors. Mazhar et al., therefore, concluded that APD-induced HN may be caused by an unbalanced inhibition of dopamine D3 and serotonin 5-HT $2 \mathrm{~A}$. Among the APDs included in Mazhar et al.'s study with the highest degree of disproportionalityand therefore higher risk for $\mathrm{HN}$-were amisulpride, flupentixol, risperidone, and olanzapine (2021). While the present study also observed $\mathrm{HN}$ under treatment with risperidone and olanzapine, flupentixol and amisulpride were not associated with the occurrence of drug-induced $\mathrm{HN}$.

The present study detected a total of 16 events of HN probably or definitely associated with APDs; APDs (as a single APD or combination of multiple APDs) were imputed exclusively in only 4 cases. While this very low number of events does not allow a robust conclusion to be drawn, the present study found a slightly higher incidence of APDinduced HN than the study by Letmaier et al. (Letmaier et al. $2012)(0.005 \%$ vs. $0.003 \%)$. In relation to their utilization rates, lp FGAs exhibited a slightly lower risk of $\mathrm{HN}$ than hp FGAs and SGAs.

\section{Concomitant drug use and HN}

When used in combination with other potentially HNinducing drugs such as DIUs (Liamis et al. 2008), ARBs, ACE-Is (Falhammar et al. 2020), and PPIs (Falhammar et al. 2019b), the incidence of HN increased dramatically among SSRI-, SSNRI-, and carbamazepine-users. Affecting $0.42 \%$ of patients, SSNRI + ARB was the drug combination (used in $\geq 1,900$ patients) with the highest risk of HN, followed by SSNRI + DIU and SSNRI + PPIHN $(0.35 \%$ each). The concomitant prescription of psychotropic drugs with a thiazide or thiazide-like diuretic is a well-described risk factor for severe $\mathrm{HN}$ through possibly complementary mechanisms (Rosner 2004; Kim et al. 2014). The use of thiazides and thiazide-like diuretics has previously been shown to increase the risk of $\mathrm{HN}$ in patients treated with psychotropic drugs by a fourfold (odds ratio $(\mathrm{OR})=4.04$, 95\% CI $=1.03-15.70$ ) (Mannesse et al. 2013), an OR which is substantially exceeded in the present study. Due to the larger study sample and higher number of registered HNs, this study provides narrower, and therefore more accurate confidence intervals for several drug combinations in comparison to the previous study by Letmaier et al. SSRI-users with concomitant use of DIUs had a tenfold higher risk for $\mathrm{HN}$, which is also higher than the risk determined by Letmaier et al. (sevenfold) (Letmaier et al. 2012). SSNRIusers concomitantly using DIUs had a 35 times greater risk that those not using DIUs in this study. In fact, incidence of $\mathrm{HN}$ in SSNRI-users without other potentially $\mathrm{HN}$-inducing dugs was minimal $(0.01 \%)$ and increased significantly (16fold to 42-fold) in combination with ACE-Is, DIUs, ARBs, PPIHNs, and PPINNs. This finding implicates that SSNRIs have a particularly high potential of exerting additive pharmacodynamic effects when used with other drugs. Moreover, in most cases presenting with severe symptoms of $\mathrm{HN}$ in this study (i.e., 36 out of 40 cases), multiple drugs were considered to be causally associated with the occurrence of $\mathrm{HN}$. This finding indicates that not only is HN more likely to occur when multiple $\mathrm{HN}$-inducing drugs are combined, but the risk of severe symptoms is also increased.

On the other hand, it has been demonstrated that the prescription of more than one potentially SIADH-inducing medication led to a higher overall prevalence of $\mathrm{HN}$ but did not impact the severity of symptoms. This finding may suggest that there are no synergistic effects between SIADH-inducing drugs (Shepshelovich et al. 2017). This may explain why the combination SSRI/SSNRI + APD did not lead to an increased risk of HN. Similarly, concomitant use of SSRIs and carbamazepine has been found not to be related to the occurrence of $\mathrm{HN}$ under treatment with APDs (Yang and Cheng 2017). In our study, concomitant use of APDs did not increase the risk of HN in SSRI and SSNRI-users.

\section{Use of PPIHN versus PPINN}

PPIs are often considered devoid of ADRs (Nachnani et al. 2015) and are liberally prescribed (Falhammar et al. 2019b). Most published case reports of PPI-induced HN were related to the use of omeprazole and esomeprazole (Ferreira et al. 2016; van der Zalm et al. 2020) which are also viewed as the PPIs with the highest risk for this overall rare PPI-induced ADR (Falhammar et al. 2019b). Lansoprazole was first reported to be involved in $\mathrm{HN}$ in 2000 (Fort et al. 2000), while indications of pantoprazole-induced $\mathrm{HN}$ arose in 2014 (Naharcý et al. 2014). In this study, PPIs are categorized as PPIHNs (i.e., omeprazole, esomeprazole, lansoprazole) or PPINNs (i.e., pantoprazole) reflecting these temporal aspects, an approach which was not previously used by Letmaier et al. (2012) as pantoprazole was still considered to be devoid of HN as an ADR at that time. This study 
demonstrates that the combined use of PPIHNs with SSRIs and SSNRIs each showed a higher risk of HN than when used with the PPINN pantoprazole. In fact, the risk of $\mathrm{HN}$ was more than twice as high among patients treated with PPIHN + SSRI than those treated with PPINN + SSRI while this discrepancy was not as pronounced among SSNRI users. These clinically relevant implications are useful in the selection of a safe drug regimen, especially when treating patients with other risk factors for $\mathrm{HN}$ (see below).

\section{Dosage and time to onset of drug-induced HN}

As found in the present study, risk of drug-induced HN appears to be the highest during the first 2-3 weeks of treatment (Liu et al. 1996; Wilkinson et al. 1999; Kirby and Ames 2001; Madhusoodanan et al. 2002; Fabian et al. 2004; Mazhar et al. 2020). About $75 \%$ of patients who suffer from SSRI-induced HN develop HN within the first 30 days of treatment. However, HN can also occur after long-term treatment (i.e., several years) (Meulendijks et al. 2010), as was also the case here.

This study found that in cases of multiple imputations, the imputed non-psychotropic drugs had often been administered for more than 3 weeks or even for more than 3 months. Due to the psychiatric inpatient setting, it is expected that psychotropic medication is more frequently adjusted than non-psychotropic medication. This consideration indicates that previously well-tolerated potentially $\mathrm{HN}$-inducing drugs are more likely to cause $\mathrm{HN}$ in combination with recently added potentially $\mathrm{HN}$-inducing psychotropic drugs. Further supporting this is that lower doses of sertraline, venlafaxine, and duloxetine were used in the treatment of patients in this study who experienced $\mathrm{HN}$ due to combinations of multiple drugs.

The occurrence of SSRI-induced HN appears to be unrelated to dose (Madhusoodanan et al. 2002; Egger et al. 2006) or plasma levels (Stedman et al. 2002; Fabian et al. 2004). Dose-dependent effects of HN were found only for oxcarbazepine in this study. While this is also reflected in literature (Lin et al. 2010; Kim et al. 2014), the present study was unable to validate the well-established dose-dependent effects described for carbamazepine (Van Amelsvoort et al. 1994; Kuz and Manssourian 2005; Holtschmidt-Täschner and Soyka 2007). If this is the case, then dose reduction may be sufficient in ameliorating HN (Kim et al. 2014).

\section{Risk factors for HN}

The occurrence of drug-induced $\mathrm{HN}$ is linked to a variety of risk factors. Concomitant use of DIUs (Siegler et al. 1995; Kirby and Ames 2001; Roxanas 2003; Letmaier et al. 2012; Mannesse et al. 2013; De Picker et al. 2014), age $\geq 65$ years (Movig et al. 2002; Wright and Schroeter 2008; Letmaier et al. 2012; De Picker et al. 2014), and female sex (Roxanas 2003; Wright and Schroeter 2008; Letmaier et al. 2012; Ramírez et al. 2019) are several of the most commonly reported risk factors of HN. Other studies were unable to identify an association with sex (Movig et al. 2002; Mannesse et al. 2013).

While often considered a safer alternative in the treatment of older adults due to their lower potential of causing antimuscarinic ADRs, patient's $\geq 65$ years of age may have a more than the sixfold increased risk in comparison to patients $<65$ years of age of developing SSRI-induced HN (Movig et al. 2002). This study was able to specifically pinpoint a significantly higher risk of $\mathrm{HN}$ in female SSNRIusers aged $\geq 65$ years, who were concomitantly treated with other potentially $\mathrm{HN}$-inducing drugs. Among diagnostic subgroups, incidence of $\mathrm{HN}$ was highest among patients with substance-related disorders, which was also considered a predisposing factor in several cases of severe symptomatic HN. Substance abuse-in particularly of alcohol-is linked with the occurrence of $\mathrm{HN}$ most commonly due to hypovolemia (Liamis et al. 2000). Previously reported risk factors of $\mathrm{HN}$, some of which this study was unable to evaluate due to missing information, include a history of cancer (Bourgeois 2005), previous HN (Fabian et al. 2004), lower BMI, and higher outdoor temperatures (Ramírez et al. 2019).

\section{Strengths and limitations}

AMSP is a structured drug surveillance program with a uniform documentation process. The 23-year observation period of nearly half a million psychiatric inpatients enables the detection of rare ADRs with a lower margin of error. Due to the inpatient setting, AMSP is able to assess actual drug utilization rates versus prescription rates, as is often the case in studies reflecting the outpatient setting. All (suspected) ADRs are rigorously analyzed and reviewed by the drug monitors, senior physicians, and by the board before they are admitted into the AMSP database to counteract possible differences in individual judgement and assessment habits.

However, the present study should also be interpreted in the context of its limitations. Depending on time, motivation, and the financial means of the participating hospital, an individual and institutional bias in terms of underreporting of ADRs cannot be excluded. Patients receiving certain drugs with a more well-known risk of HN such as oxcarbazepine and carbamazepine may have been more closely monitored for the occurrence of $\mathrm{HN}$ than patients treated with drugs rarely associated with $\mathrm{HN}$. However, it is expected that this collective of inpatients is more closely monitored for changes in laboratory values than outpatients due to routine blood collection. As most cases of HN in this study presented without symptoms or unspecific symptoms, that may 
be mistaken for a worsening of mental illness, complicating detection of $\mathrm{HN}$ in this specific study population. Drug monitors documenting the ADRs were often not directly involved in the treatment of the patients, therefore the description of ADRs could only be provided by the treating physician or their documentation. This may have resulted in a larger quantity of asymptomatic cases of HN. Due to AMSP's strict criteria for inclusion of drug-induced $\mathrm{HN}$ in its database, the present study detected rates of $\mathrm{HN}$ much lower than other authors. While on the one hand this thorough screening and evaluation of ADR cases is beneficial and more accurately reflects the actual clinical relevance of ADRs, it also contributes to under-reporting. Furthermore, the results presented here may not represent the risk of $\mathrm{HN}$ in the ambulatory setting. Psychiatric inpatients are generally more severely ill and may also suffer from a higher degree of comorbidity, therefore potentially resulting in higher concomitant use of psychotropic and non-psychotropic drugs.

\section{Conclusion}

As revealed in the present study, $\mathrm{HN}$ is a potential ADR of most antidepressant and antipsychotic drugs and is most likely to occur within the first weeks of treatment. While cases often presented without any clinical symptoms, severe symptoms such as seizures, coma, and delirium are potentially life-threatening and can result in permanent damage. The risk of HN varied among the various classes of psychotropic drugs. AEDs-especially carbamazepine and oxcarbazepine-were most likely to cause drug-induced $\mathrm{HN}$. Among ADDs, SSRI and SSNRIs presented the highest risk of HN, while NaSSAs and TCAs were only rarely associated with HN. In comparison to ADDs as a group, APDs showed a much lower risk of HN. The risk of HN under treatment with SSRIs, SSNRIs, and carbamazepine increased significantly when combined with other potentially $\mathrm{HN}$-inducing drugs used in the treatment of internal illnesses such as DIUs, ACE-Is, ARBs, and PPIs. This study found that women aged 65 years and older treated with SSNRIs with concomitant drug use had a particularly high risk of developing drug-induced HN. The identification of specific at-risk patient groups and high-risk drug combinations facilitates the implementation of drug safety in a clinically relevant manner.

Acknowledgements The authors would like to thank all psychiatric hospitals participating in the AMSP project for their continuous support in data collection.

Funding Open Access funding enabled and organized by Projekt DEAL. The research presented in this manuscript did not receive any specific grants or funding. The AMSP drug safety project is facilitated by non-profit associations in Germany, Austria, and Switzerland. The AMSP project has been supported with unrestricted educational and research grants since 1993 by the following companies. German companies: Abbott GmbH \& Co. KG, AstraZeneca GmbH, Aventis Pharma Deutschland GmbH GE-O/R/N, Bayer Vital GmbH, Boehringer Mannheim GmbH, Bristol-Myers-Squibb, Ciba Geigy GmbH, Desitin Arzneimittel GmbH, Duphar Pharma GmbH \& Co. KG, Eisai GmbH, Esparma GmbH Arzneimittel, GlaxoSmithKline Pharma GmbH \& Co. KG, Hoffmann-La Roche AG Medical Affairs, Janssen-Cilag GmbH, Janssen Research Foundation, Knoll Deutschland GmbH, Lilly Deutschland GmbH Niederlassung Bad Homburg, Lundbeck GmbH \& Co. KG, Novartis Pharma GmbH, Nordmark Arzneimittel GmbH, Organon GmbH, Otsuka-Pharma Frankfurt, Pfizer GmbH, Pharmacia \& Upjohn GmbH, Promonta Lundbeck Arzneimittel, Recordati Pharma GmbH, Rhone-Poulenc Rohrer, Sanofi-Synthelabo GmbH, SanofiAventis Deutschland, Schering AG, SmithKlineBeecham Pharma $\mathrm{GmbH}$, Solvay Arzneimittel GmbH, Synthelabo Arzneimittel GmbH, Dr. Wilmar Schwabe GmbH \& Co., Thiemann Arzneimittel GmbH, Troponwerke GmbH \& Co. KG, Upjohn GmbH, Wander Pharma $\mathrm{GmbH}$, and Wyeth-Pharma GmbH. Austrian companies: Astra Zeneca Österreich $\mathrm{GmbH}$, Boehringer Ingelheim Austria, Bristol-Myers Squibb GmbH, CSC Pharmaceuticals GmbH, Eli Lilly GmbH, Germania Pharma GmbH, GlaxoSmithKline Pharma GmbH, Janssen-Cilag Pharma GmbH, Lundbeck GmbH, Novartis Pharma GmbH, Pfizer Med Inform, and Wyeth Lederle Pharma GmbH. Swiss companies: AHP (Schweiz) AG, AstraZeneca AG, Bristol-Myers Squibb AG, Desitin Pharma GmbH, Eli Lilly (Suisse) S.A., Essex Chemie AG, GlaxoSmithKline AG, Janssen-Cilag AG, Lundbeck (Suisse) AG, Organon AG, Pfizer AG, Pharmacia, Sanofi-Aventis (Suisse) S.A., Sanofi-Synthelabo SA, Servier SA, SmithKlineBeecham AG, Solvay Pharma AG, Wyeth AHP (Suisse) AG, and Wyeth Pharmaceuticals AG.

\section{Declarations}

Conflict of interest JS took part in an educational event sponsored by Otsuka/Lundbeck. ST is a member of the advisory board for Otsuka and Janssen-Cilag and has received speaker's honoraria from JanssenCilag, Lundbeck/Otsuka, Recordati Pharma GmbH, and Servier. All other authors state they have no conflicts of interest to declare.

Open Access This article is licensed under a Creative Commons Attribution 4.0 International License, which permits use, sharing, adaptation, distribution and reproduction in any medium or format, as long as you give appropriate credit to the original author(s) and the source, provide a link to the Creative Commons licence, and indicate if changes were made. The images or other third party material in this article are included in the article's Creative Commons licence, unless indicated otherwise in a credit line to the material. If material is not included in the article's Creative Commons licence and your intended use is not permitted by statutory regulation or exceeds the permitted use, you will need to obtain permission directly from the copyright holder. To view a copy of this licence, visit http://creativecommons.org/licenses/by/4.0/.

\section{References}

Ajlouni K, Kern MW, Tures JF, Theil GB, Hagen TC (1974) Thiothixene-induced hyponatremia. Arch Intern Med 134(6):1103-1105. https://doi.org/10.1001/archinte.1974.00320240137019

Bahar MA, Kamp J, Borgsteede SD, Hak E, Wilffert B (2018) The impact of CYP2D6 mediated drug-drug interaction: a systematic review on a combination of metoprolol and paroxetine/fluoxetine. 
Br J Clin Pharmacol 84(12):2704-2715. https://doi.org/10.1111/ bcp. 13741

Bourgeois JA (2005) Reversible hyponatremia and venlafaxine. Psychosomatics 46(5):495-496. https://doi.org/10.1176/appi.psy. 46.5.495

Bullmann C (2016) Hyponatriämie. Arzneimittelverordnung in Der Praxis 24:188-194

Coupland C, Dhiman P, Morriss R, Arthur A, Barton G, HippisleyCox J (2011a) Antidepressant use and risk of adverse outcomes in older people: population based cohort study. BMJ 343:d4551. https://doi.org/10.1136/bmj.d4551

Coupland CA, Dhiman P, Barton G, Morriss R, Arthur A, Sach T, Hippisley-Cox J (2011b) A study of the safety and harms of antidepressant drugs for older people: a cohort study using a large primary care database. Health Technol Assess 15(28):1-202. https:// doi.org/10.3310/hta15280

De Picker L, Van Den Eede F, Dumont G, Moorkens G, Sabbe BG (2014) Antidepressants and the risk of hyponatremia: a class-byclass review of literature. Psychosomatics 55(6):536-547. https:// doi.org/10.1016/j.psym.2014.01.010

Degner D, Grohmann R, Kropp S, Rüther E, Bender S, Engel RR, Schmidt LG (2004) Severe adverse drug reactions of antidepressants: results of the German multicenter drug surveillance program AMSP. Pharmacopsychiatry 37(Suppl 1):S39-45. https:// doi.org/10.1055/s-2004-815509

Dineen R, Thompson CJ, Sherlock M (2017) Hyponatraemia-presentations and management. Clin Med 17(3):263-269. https://doi. org/10.7861/clinmedicine.17-3-263

Druschky K, Bleich S, Grohmann R, Engel RR, Kleimann A, Stübner S, Greil W, Toto S (2018) Use and safety of antiepileptic drugs in psychiatric inpatients-data from the AMSP study. Eur Arch Psychiatry Clin Neurosci 268(2):191-208. https://doi.org/10.1007/ s00406-017-0827-5

Dundas B, Harris M, Narasimhan M (2007) Psychogenic polydipsia review: etiology, differential, and treatment. Curr Psychiatry Rep 9(3):236-241. https://doi.org/10.1007/s11920-007-0025-7

Egger C, Muehlbacher M, Nickel M, Geretsegger C, Stuppaeck C (2006) A review on hyponatremia associated with SSRIs, reboxetine and venlafaxine. Int J Psychiatry Clin Pract 10(1):17-26. https://doi.org/10.1080/13651500500410216

Fabian TJ, Amico JA, Kroboth PD, Mulsant BH, Corey SE, Begley AE, Bensasi SG, Weber E, Dew MA, Reynolds CF, Pollock BG (2004) Paroxetine-induced hyponatremia in older adults: a 12-week prospective study. Arch Intern Med 164(3):327-332. https://doi.org/ 10.1001/archinte.164.3.327

Falhammar H, Lindh JD, Calissendorff J, Farmand S, Skov J, Nathanson D, Mannheimer B (2018) Differences in associations of antiepileptic drugs and hospitalization due to hyponatremia: a population-based case-control study. Seizure 59:28-33. https:// doi.org/10.1016/j.seizure.2018.04.025

Falhammar H, Lindh JD, Calissendorff J, Skov J, Nathanson D, Mannheimer B (2019a) Antipsychotics and severe hyponatremia: a Swedish population-based case-control study. Eur J Intern Med 60:71-77. https://doi.org/10.1016/j.ejim.2018.11.011

Falhammar H, Lindh JD, Calissendorff J, Skov J, Nathanson D, Mannheimer B (2019b) Associations of proton pump inhibitors and hospitalization due to hyponatremia: a population-based casecontrol study. Eur J Intern Med 59:65-69. https://doi.org/10. 1016/j.ejim.2018.08.012

Falhammar H, Skov J, Calissendorff J, Nathanson D, Lindh JD, Mannheimer B (2020) Associations Between antihypertensive medications and severe hyponatremia: a Swedish population-based case-control study. J Clin Endocrinol Metab 105(10):e3696e3705. https://doi.org/10.1210/clinem/dgaa194

Farmand S, Lindh JD, Calissendorff J, Skov J, Falhammar H, Nathanson D, Mannheimer B (2018) Differences in associations of antidepressants and hospitalization due to hyponatremia. Am J Med 131(1):56-63. https://doi.org/10.1016/j.amjmed.2017.07.025

Ferguson JM, Hill H (2006) Pharmacokinetics of fluoxetine in elderly men and women. Gerontology 52(1):45-50. https://doi.org/10. $1159 / 000089825$

Ferreira F, Mateus S, Santos AR, Moreira H, Ferreira NR (2016) Pantoprazole-related Symptomatic Hyponatremia. Eur J Case Rep Intern Med 3(2):000341. https://doi.org/10.12890/2015_000341

Fort E, Laurin C, Baroudi A, Liebaert-Bories MP, Strock P (2000) Lansoprazole-induced hyponatremia. Gastroenterol Clin Biol 24(6-7):686

Gandhi S, McArthur E, Reiss JP, Mamdani MM, Hackam DG, Weir MA, Garg AX (2016) Atypical antipsychotic medications and hyponatremia in older adults: a population-based cohort study. Can J Kidney Health Dis 3:21. https://doi.org/10.1186/ s40697-016-0111-z

Gankam Kengne F, Andres C, Sattar L, Melot C, Decaux G (2008) Mild hyponatremia and risk of fracture in the ambulatory elderly. QJM 101(7):583-588. https://doi.org/10.1093/qjmed/hcn061

Gankam-Kengne F, Ayers C, Khera A, de Lemos J, Maalouf NM (2013) Mild hyponatremia is associated with an increased risk of death in an ambulatory setting. Kidney Int 83(4):700-706. https:// doi.org/10.1038/ki.2012.459

Grohmann R, Engel RR, Rüther E, Hippius H (2004) The AMSP drug safety program: methods and global results. Pharmacopsychiatry 37(Suppl 1):S4-11. https://doi.org/10.1055/s-2004-815505

Grohmann R, Engel RR, Möller HJ, Rüther E, van der Velden JW, Stübner S (2014) Flupentixol use and adverse reactions in comparison with other common first- and second-generation antipsychotics: data from the AMSP study. Eur Arch Psychiatry Clin Neurosci 264(2):131-141. https://doi.org/10.1007/s00406-013-0419-y

Holtschmidt-Täschner B, Soyka M (2007) Hyponatremia-induced seizure during carbamazepine treatment. World J Biol Psychiatry 8(1):51-53. https://doi.org/10.1080/15622970600960157

Hwang AS, Magraw RM (1989) Syndrome of inappropriate secretion of antidiuretic hormone due to fluoxetine. Am J Psychiatry 146(3):399. https://doi.org/10.1176/ajp.146.3.399a

Intravooth T, Staack AM, Juerges K, Stockinger J, Steinhoff BJ (2018) Antiepileptic drugs-induced hyponatremia: review and analysis of 560 hospitalized patients. Epilepsy Res 143:7-10. https://doi. org/10.1016/j.eplepsyres.2018.03.023

Jacob S, Spinler SA (2006) Hyponatremia associated with selective serotonin-reuptake inhibitors in older adults. Ann Pharmacother 40(9):1618-1622. https://doi.org/10.1345/aph.1G293

Kim YS, Kim DW, Jung KH, Lee ST, Kang BS, Byun JI, Yeom JS, Chu K, Lee SK (2014) Frequency of and risk factors for oxcarbazepine-induced severe and symptomatic hyponatremia. Seizure 23(3):208-212. https://doi.org/10.1016/j.seizure.2013.11.015

Kirby D, Ames D (2001) Hyponatraemia and selective serotonin re-uptake inhibitors in elderly patients. Int J Geriatr Psychiatry 16(5):484-493. https://doi.org/10.1002/gps.367

Knigge U, Willems E, Kjaer A, Jørgensen H, Warberg J (1999) Histaminergic and catecholaminergic interactions in the central regulation of vasopressin and oxytocin secretion. Endocrinology 140(8):3713-3719. https://doi.org/10.1210/endo.140.8.6891

Kuz GM, Manssourian A (2005) Carbamazepine-induced hyponatremia: assessment of risk factors. Ann Pharmacother 39(11):1943-1946. https://doi.org/10.1345/aph.1G209

Letmaier M, Painold A, Holl AK, Vergin H, Engel R, Konstantinidis A, Kasper S, Grohmann R (2012) Hyponatraemia during psychopharmacological treatment: results of a drug surveillance programme. Int J Neuropsychopharmacol 15(6):739-748. https://doi. org/10.1017/s1461145711001192

Liamis GL, Milionis HJ, Rizos EC, Siamopoulos KC, Elisaf MS (2000) Mechanisms of hyponatraemia in alcohol patients. Alcohol Alcohol 35(6):612-616. https://doi.org/10.1093/alcalc/35.6.612 
Liamis G, Milionis H, Elisaf M (2008) A review of drug-induced hyponatremia. Am J Kidney Dis 52(1):144-153. https://doi.org/ 10.1053/j.ajkd.2008.03.004

Lin $\mathrm{CH}$, Lu CH, Wang FJ, Tsai MH, Chang WN, Tsai NW, Lai SL, Tseng YL, Chuang YC (2010) Risk factors of oxcarbazepineinduced hyponatremia in patients with epilepsy. Clin Neuropharmacol 33(6):293-296. https://doi.org/10.1097/WNF.0b013e3181 f80bd4

Liu BA, Mittmann N, Knowles SR, Shear NH (1996) Hyponatremia and the syndrome of inappropriate secretion of antidiuretic hormone associated with the use of selective serotonin reuptake inhibitors: a review of spontaneous reports. CMAJ 155(5):519-527

Madhusoodanan S, Bogunovic OJ, Moise D, Brenner R, Markowitz S, Sotelo J (2002) Hyponatraemia associated with psychotropic medications. A review of the literature and spontaneous reports. Adverse Drug React Toxicol Rev 21(1-2):17-29. https://doi.org/ 10.1007/bf03256181

Mannesse CK, Jansen PA, Van Marum RJ, Sival RC, Kok RM, Haffmans PM, Egberts TC (2013) Characteristics, prevalence, risk factors, and underlying mechanism of hyponatremia in elderly patients treated with antidepressants: a cross-sectional study. Maturitas 76(4):357-363. https://doi.org/10.1016/j.maturitas. 2013.08.010

Mazhar F, Pozzi M, Gentili M, Scatigna M, Clementi E, Radice S, Carnovale C (2019) Association of hyponatraemia and antidepressant drugs: a pharmacovigilance-pharmacodynamic assessment through an analysis of the US Food and Drug Administration Adverse Event Reporting System (FAERS) Database. CNS Drugs 33(6):581-592. https://doi.org/10.1007/s40263-019-00631-5

Mazhar F, Carnovale C, Haider N, Ahmed R, Taha M (2020) Paliperidone-associated hyponatremia: report of a fatal case with analysis of cases reported in the literature and to the US Food and Drug Administration Adverse Event Reporting System. J Clin Psychopharmacol 40(2):202-205. https://doi.org/10.1097/jcp.0000000000 001180

Mazhar F, Battini V, Pozzi M, Invernizzi E, Mosini G, Gringeri M, Capuano A, Scavone C, Radice S, Clementi E, Carnovale C (2021) Hyponatraemia following antipsychotic treatment: In-silico pharmacodynamics analysis of spontaneous reports from the US Food and Drug Administration Adverse Event Reporting System Database and an updated systematic review. Int J Neuropsychopharmacol. https://doi.org/10.1093/ijnp/pyab005

Meulendijks D, Mannesse CK, Jansen PA, van Marum RJ, Egberts TC (2010) Antipsychotic-induced hyponatraemia: a systematic review of the published evidence. Drug Saf 33(2):101-114. https://doi. org/10.2165/11319070-000000000-00000

Movig KL, Leufkens HG, Lenderink AW, van den Akker VG, Hodiamont PP, Goldschmidt HM, Egberts AC (2002) Association between antidepressant drug use and hyponatraemia: a case-control study. Br J Clin Pharmacol 53(4):363-369. https://doi.org/10. 1046/j.1365-2125.2002.01550.x

Nachnani J, Bulchandani D, Bulchandani S (2015) Severe hyponatremia associated with the use of pantoprazole. Am J Gastroenterol 110:S264

Naharcý MI, Cintosun U, Ozturk A, Bozoglu E, Doruk H (2014) Pantoprazole sodium-induced hyponatremia in a frail elderly adult. $\mathrm{J}$ Am Geriatr Soc 62(4):787-788. https://doi.org/10.1111/jgs.12767

Palmer S, Vecchio M, Craig JC, Tonelli M, Johnson DW, Nicolucci A, Pellegrini F, Saglimbene V, Logroscino G, Fishbane S, Strippoli GFM (2013) Prevalence of depression in chronic kidney disease: systematic review and meta-analysis of observational studies. Kidney Int 84(1):179-191. https://doi.org/10.1038/ki.2013.77

Peck V, Shenkman L (1979) Haloperidol-induced syndrome of inappropriate secretion of antidiuretic hormone. Clin Pharmacol Ther 26(4):442-444. https://doi.org/10.1002/cpt1979264442
Ramírez E, Rodríguez A, Queiruga J, García I, Díaz L, Martínez L, Muñoz R, Muñoz M, Tong HY, Martínez JC, Borobia AM, Carcas AJ, Frías J (2019) Severe hyponatremia is often drug induced: 10-year results of a prospective pharmacovigilance program. Clin Pharmacol Ther 106(6):1362-1379. https://doi.org/10.1002/cpt. 1562

Renneboog B, Musch W, Vandemergel X, Manto MU, Decaux G (2006) Mild chronic hyponatremia is associated with falls, unsteadiness, and attention deficits. Am J Med 119(1):71.e7178. https://doi.org/10.1016/j.amjmed.2005.09.026

Rosner MH (2004) Severe hyponatremia associated with the combined use of thiazide diuretics and selective serotonin reuptake inhibitors. Am J Med Sci 327(2):109-111. https://doi.org/10.1097/ 00000441-200402000-00012

Roxanas MG (2003) Mirtazapine-induced hyponatraemia. Med J Aust 179(8):453-454. https://doi.org/10.5694/j.1326-5377.2003.tb056 35. $\mathrm{x}$

Shepshelovich D, Schechter A, Calvarysky B, Diker-Cohen T, RozenZvi B, Gafter-Gvili A (2017) Medication-induced SIADH: distribution and characterization according to medication class. $\mathrm{Br}$ J Clin Pharmacol 83(8):1801-1807. https://doi.org/10.1111/bcp. 13256

Siegler EL, Tamres D, Berlin JA, Allen-Taylor L, Strom BL (1995) Risk factors for the development of hyponatremia in psychiatric inpatients. Arch Intern Med 155(9):953-957

Spasovski G, Vanholder R, Allolio B, Annane D, Ball S, Bichet D, Decaux G, Fenske W, Hoorn EJ, Ichai C, Joannidis M, Soupart A, Zietse R, Haller M, van der Veer S, Van Biesen W, Nagler E (2014) Clinical practice guideline on diagnosis and treatment of hyponatraemia. Nephrol Dial Transplant 29(Suppl 2):i1-i39. https://doi.org/10.1093/ndt/gfu040

Spigset O, Hedenmalm K (1995) Hyponatraemia and the syndrome of inappropriate antidiuretic hormone secretion (SIADH) induced by psychotropic drugs. Drug Saf 12(3):209-225. https://doi.org/ 10.2165/00002018-199512030-00006

Stedman CA, Begg EJ, Kennedy MA, Roberts R, Wilkinson TJ (2002) Cytochrome P450 2D6 genotype does not predict SSRI (fluoxetine or paroxetine) induced hyponatraemia. Hum Psychopharmacol 17(4):187-190. https://doi.org/10.1002/hup.394

Strachan J, Shepherd J (1998) Hyponatraemia associated with the use of selective serotonin re-uptake inhibitors. Aust N Z J Psychiatry 32(2):295-298. https://doi.org/10.3109/00048679809062743

Van Amelsvoort T, Bakshi R, Devaux CB, Schwabe S (1994) Hyponatremia associated with carbamazepine and oxcarbazepine therapy: a review. Epilepsia 35(1):181-188. https://doi.org/10.1111/j.15281157.1994.tb02930.x

van der Zalm IJB, Tobé TJM, Logtenberg SJJ (2020) Omeprazoleinduced and pantoprazole-induced asymptomatic hyponatremia: a case report. J Med Case Reports 14(1):83. https://doi.org/10. 1186/s13256-020-02423-8

Verbalis JG, Barsony J, Sugimura Y, Tian Y, Adams DJ, Carter EA, Resnick HE (2010) Hyponatremia-induced osteoporosis. J Bone Miner Res 25(3):554-563. https://doi.org/10.1359/jbmr.090827

Vollset SE (1993) Confidence intervals for a binomial proportion. Stat Med 12(9):809-824. https://doi.org/10.1002/sim.4780120902

Wilkinson TJ, Begg EJ, Winter AC, Sainsbury R (1999) Incidence and risk factors for hyponatraemia following treatment with fluoxetine or paroxetine in elderly people. Br J Clin Pharmacol 47(2):211217. https://doi.org/10.1046/j.1365-2125.1999.00872.x

Wright SK, Schroeter S (2008) Hyponatremia as a complication of selective serotonin reuptake inhibitors. J Am Acad Nurse Pract 20(1):47-51. https://doi.org/10.1111/j.1745-7599.2007.00280.x

Yang HJ, Cheng WJ (2017) Antipsychotic use is a risk factor for hyponatremia in patients with schizophrenia: a 15-year followup study. Psychopharmacology 234(5):869-876. https://doi.org/ 10.1007/s00213-017-4525-9 
Yip TC, Wong GL, Tse YK, Yuen BW, Luk HW, Lam MH, Li MK, Loo CK, Tsang OT, Tsang SW, Chan HL, Wing YK, Wong VW. High incidence of hepatocellular carcinoma and cirrhoticcomplications in patients with psychiatric illness: a territory-wide cohort study. BMC Gastroenterol. 2020;20(1):128. https://doi.org/10.1186/ s12876-020-01277-0. PMID: 32349708; PMCID:PMC7189713.
Publisher's Note Springer Nature remains neutral with regard to jurisdictional claims in published maps and institutional affiliations. 